\title{
Tracing the causality between Livestock and poverty alleviation in the rural economy of Gilgit Baltistan-Pakistan
}

\author{
Gulnaz Hameed ${ }^{1 *}$, Shagufta Shaheen ${ }^{1}$, Abdul Saboor ${ }^{1}$, and Khuram Nawaz Sadozai ${ }^{2}$ \\ ${ }^{1}$ Department of Economics, UAAR, Pakistan \\ ${ }^{2}$ Assistant Professor, Department of Agriculture and Applied Economics, UAP, Pakistan
}

\begin{abstract}
Livestock rearing and its production are deemed as a lucrative economic activity which provides livelihood and sustainable growth to rural population of Gilgit Baltistan . This sector not only delivers variety of food and non-food products but also contributes in income generation and subsequently diminishes the rural poverty. The fundamental aim of this research endeavor was to assess the poverty status and its determinants for livestock growers of the study area. The primary data was gleaned from 100 respondents through interview schedule following systematic sampling procedure. Uni-dimensional poverty estimates for sampled respondents employing Foster, Greer, and Thorbecke (FGT) poverty index are incorporated as dependent variable to model the binary probability expressions through Logit. Out of Explanatory variables used in model, benefit from the livestock, age, form size and gender of household head, showed a significant but negative relationship with poverty status whereas, household size and education of household head had a insignificant influence on poverty. This study recommends, that increase in farm size and youth's participation in livestock farming can elevate the household income. The capacity building of the livestock farmers through trainings and more women contribution in livestock sector should be encouraged to reduce poverty in the area which can play a remarkable role in sustainable economic growth.
\end{abstract}

\section{Introduction}

Agriculture is the lifeline for developing countries and contribution of livestock in agricultural sector has been 40 Percent globally and thirty percent in developing countries [19]. Two thirds of the world population kept domestic animals for their needs, from which 90 Percent were owned by rural smallholders [18]. Livestock provides food security, food nutrition and contributes to income generation which implies that growth in the livestock

* Correspondent Author: gulnazhameed@yahoo.com 
sector offers a chance to alleviate/decrease poverty by providing food safety and improving the livelihoods of smallholder households $[21,32,16]$ and thus plays a valuable role for sustainable agriculture especially in developing countries [42].

According to estimation the production of livestock globally valued about 883 billion dollars [22]. The economic benefits from livestock are further extended to upstream industry e.g. producers and transporters of feed, manufacturers of equipment and vaccines and seed companies etc. , downstream industries like butchers, milk processors, retailers , wholesalers etc. and allied services including veterinarians, dietary specialists etc. A variety of products (food and non-food) including milk, Dairy products, meat, eggs, wool, leather, bone products, pharmaceuticals, fats and industrial proteins are obtained from animals. Even animal wastes may not be wasted like intestines may further be utilized as crop fertilizer. Animal dung/manure is helpful not only in maintaining the land fertility but also used as fuel. Moreover, some types of cattle are used for on farm mechanical purposes (tillage etc.) and also for transport of folks and goods in regions with inadequate machine power $[38,52,39]$. So the production of livestock not only serve as the source of earning income but a major contributing factor to economic and food security and can be considered as cover/insurance in case of any hazard [19, 3]. For diversifying sources of income some of the farmers are reported to rear livestock as a tactic to lessen the chance of risks associated to climate, marketing conditions and other issues [34, 31].There are studies which also highlighted the social importance (besides economic value) of livestock in developing economies with rural poverty areas and is not restricted to nomadic or country side cultures only $[1,2]$.Even in developed nations rearing animals are crucial in maintaining the cultural values and connections of people to forefather's land and animals and so to whole community and it has been accepted even at low rate of return from ranching $[6,10,46]$.

Due to extensive worldwide variation of cultivation practices in agriculture, the impact of producing meat on environment also varies across the regions. Some of the methods of meat production are intensive livestock farming, free range agribusiness, organic farming, fishing, and subsistence farming etc. Some of the negative effects of livestock production which have been reported are pollution due to fossil fuel, discharge of wastes and consumption of land and water. [20] reported this sector as a major stressing factor on ecosystems, source of greenhouse gases and also causes damage to biodiversity.

In spite of these effects one cannot deny the importance of livestock in economic activities, [51] analyzed the effectiveness of livestock based micro enterprises on poverty reduction in Sunsari district of Nepal using Cross-sectional data. Results regarding this study showed that livestock based micro enterprises are effective in generating income to reduce poverty. It was concluded the livestock is important for producing food, generating income and employment. Livestock sector has a significant share in agricultural GDP [49, $35]$ of the country. Livestock sector provides many products to rural people but there are certain threats such as lack of livestock market and social off-limits etc. [40].

World Bank [54] attempts to explore that the world's livestock division has changing rapidly through a strong as well rising demand so if it will have risen up commercially livestock can be helpful for reduction of poverty. Shugri [17] determined the various dimensions of agro-pastoral household as well as the poverty status and factors determining poverty. The cross-sectional data was used to measure poverty through FGT and logistic regression model was then employed for finding poverty correlates. The findings of binary logit model showed that number of livestock, farm size, expenditure, farm income, Oxen Ownership had a significant and negative effect towards the poverty. Based on empirical findings this study recommended to improve livestock market, improve infrastructure and remove inequalities among gender. 
[23]The socio-economic factors affecting the household decision to rear livestock were identified. Three analytical techniques were used in this study. Heckman selection model, Ordinary Least Square and logistic regression model were used to analyze the data. The findings revealed that gender, age of household head, benefit from livestock and total family size has a significant effect towards probability to own cattle. Several recommendations were anticipated in this study such as to inspire youth to participate in livestock, eliminate inequalities among gender, encourage women in decision making and enhance the livestock provision institution.

In Pakistan, agricultural sector contributes importantly in economic growth as its share is nineteen point five three percent of Gross Domestic Product (GDP) with a growth rate of three point four six percent. About forty five percent of total labor force is engaged while livelihood of approximately sixty two percent of rural population depends directly or indirectly on this sector. In agriculture, the livestock sector accounts fifty eight point three percent, eleven point nine percent in GDP and it grew by three point four three percent as compared to last year growth rate of three point three six percent [27].

Rehman[7]highlighted the performance of livestock production including poultry product and explored the association between the livestock output (Products) and GDP in Pakistan over a tenure from 1980 to 2015 . It was concluded that livestock production and GDP has a positive and significant relationship so the Government should provide incentives to producers and further schemes for development of livestock sector.

[43]It was analyzed that livestock is one of key source of income to local residence of economy and essential for rural livelihood. Sample of 137 respondents were taken whose livelihood depends on livestock in Pindsultani district of Attock. Qualitative analysis was used for livestock role in rural livelihood and its contribution to local residents. The results of this study showed that animal husbandry is significant for rural economies of Pakistan and is a source of livelihood poor rural people

The Northern Areas of Pakistan situated between Karakorum, Western Himalayas and Hindu Kush mountain ranges. Approximately one million of people living in northern areas of Pakistan are governed on livestock for annually income [9]. Gilgit Baltistan earlier a part of northern areas is a beautiful mountainous region of Pakistan in which an enormous number of households depends on agriculture as well as on livestock to uplift their income and livelihood standards. Surveys of farmer's reason for keeping livestock indicated domestic milk supply as being primary source and the second purpose is for dung production which is used as fertilizer for crops production [28].

Livestock sector's contribution is continuously increasing not only to rural economy but for the country's economy as well but there is still lack of critical analysis of its benefits and associated problems for future planning. So the current research is carried out to bridge the gap of this analytical deficiency especially in the area like GilgitBaltistan by exploring the socio-economic conditions of household of the area, assessing the impact of livestock on household poverty and filter the impact of livestock production on livelihood of respondents to give some policy recommendation for future.

\section{Research Methodology}

This section includes data collection technique, source of data and sample design. The conceptual and analytical framework is also given as a sub sections.

\subsection{Data Collection}

\subsubsection{Locale}


The study was conducted in Gilgit- Baltistan, Pakistan which comprises of eight districts. Out of eight districts, three districts Hunza, Nagar and Gilgit were selected purposively. Three villages from each district were chosen and surveyed. Misghar, Ispenj, Sher-e-baz; from Hunza, Thole, Chamiling and Gutas from Nagar and Nomal, Oshkhandas and Sultanabad were selected from Gilgit purposively.

\subsubsection{Sample Size}

The formula for sample size is called proportion sample [50](Yamane, 1967). The formula is

$$
\mathrm{n}=\frac{N}{1+N(e)^{2}}
$$

Where $\mathrm{N}=$ Population Research, $\mathrm{n}=$ Sample Size, e =Level of Confidence

Our research population is 102078 . So " $\mathrm{N}$ "is 102078 and e is taken 90 Percent. Then, a sample size of 100 household is selected.

\subsection{Data Collection}

Properly designed interview schedule including both open and closed ended questions was used to collect information from livestock growers regarding demographic characteristics production of livestock and its products, as well as problems related to livestock like lack of markets, feeding problems and many other problems facing by the farmers involved in livestock keeping. Questionnaire was design in English, translated and explained in local language. The purpose of survey was to gather information about the socio- economic opportunities and challenges faced by the farmer during keeping livestock and benefits/ gain from livestock etc.

\section{Analytical Framework}

This study includes data analysis in three phases. First phase involves descriptive analysis second phase estimates unidimensional poverty and in last phase logit model applied to determine the correlates of poverty in the study area.

\subsection{Descriptive Statistic}

It is a comprehensive description of the data and it converts the data in a sophisticated manner to establish the effects of quantitative data [45].

\subsection{Poverty Estimation}

In order to estimate Unidimensional poverty of sampled respondents of the research area first step is to set the poverty line or the threshold level under which the households are thought to be poor and it was set based on the Cost of the Basic Needs (CBN) method. According to Economic Survey of Pakistan, poverty line for year 2013-14 was Rs.3030 $(\mathrm{CBN})$ which is inflated through Consumer Price Index to get poverty line of Rs. 3401.82 for the year 2016-17. Then poverty was calculated by applying FGT index (Foster-GreerThorbecke, 1984). Through FGT measure Head Count Ratio (HCR), Poverty Gap Ratio (PGR) and Squared Poverty Gap Ratio (SPGR) can be estimated by using formula: 


$$
\mathrm{FGT} \alpha=\frac{1}{N} \sum_{i=1}^{N}\left[\left(\frac{Z-Y_{i}}{Z}\right)\right] \alpha
$$

Where $\mathrm{N}$ is total number of respondents, $\mathrm{Z}$ is the poverty line as estimated and $\mathrm{Y}$ shows the consumption expenditure per person $\alpha$ may take the value of 0,1 and 2 for estimating HCR, PGR and SPGR respectively. HCR or incidence of poverty is used to quantify the percentage of poverty form over the entire population by dividing number of poor persons with total population. PGR shows how much households are far away from poverty line and figure out the mean distance under the poverty threshold means depth of poverty. While SPGR measure the average value of the square of depth of poverty intended for every household. It measure the severity of poverty by attaching more weight to the more deprived thus explains the inequality across the poor [8]. In addition the one is far from the poverty line, the larger the weight as well the severity of poverty [30].

\subsection{Specification of Logistic Model}

As in this study respondents are divided in poor and non-poor by estimating poverty so this binary relation converts the data limit in 1 or 0 forms. Distinctive method used to solve dichotomy variables is logistic regression. Major reason of using the logistic regression model is that the dependent variable is composed in the form of binary $(0,1)$ values $[24$, 13] while OLS regression method is inefficient in parameter estimations as well as heteroscedastic error correction. Consequently, the hypothesis testing and construction of confidence interval turn inaccurate and misleading [29]. So, to solve these problems and to generate relevant outcomes commonly used qualitative response a model is known as logit model [47]. In this model dependent variable takes the value of 1 if the individuals lie under the poverty line such as the poor through the probability as $\mathrm{Pi}$, if not than value be 0 such as the non-poor by the probability is $1-\mathrm{Pi}[33,44,26,48]$.

In this study respondent's estimated poverty is a binomial quantitative dependent variable and takes the value of 0 and 1, 1 if household is poor and 0 if household is non poor. Model analyses probability of household poverty status with respect to different independent variables which could be numeric as well as nominal in the form of dummies. Relationship between the probability of dependent variable is equal to one as $\mathrm{Y}=1$, while the independent variables are determined through Logit function which is logarithms of odd $\mathrm{Y}=1$. It is assumed that the value of $\mathrm{Y}$ depends on the on value of $\mathrm{X}_{1} \ldots \mathrm{X}_{\mathrm{K}}$.

General Formula of logit Model is

$$
\ln \left(\frac{Y_{i}}{1-Y_{i}}\right)=\mathrm{L}_{\mathrm{i}}=\beta_{0}+\beta_{1} \mathrm{X}_{1}+\ldots \ldots \ldots \ldots \beta_{\mathrm{k}} \mathrm{X}_{\mathrm{k}}+\mu_{\mathrm{i}}
$$

Where $\frac{Y_{i}}{1-Y_{i}}$ is the Odd Ratio:

$Y_{i}=$ Poor Household Probability, $1-Y_{i}=$ Non Poor Household Probability, $\beta_{0} \ldots \ldots \beta_{k}=$ estimated parameters, $\mathrm{X}_{\mathrm{i}} \ldots . . \mathrm{X}_{\mathrm{k}}=$ independent variables, $\mu_{\mathrm{i}}=$ error term/disturbance term

The specific model is written as:

$$
L_{i}=\beta_{0}+\beta_{1} \text { hhsize }+\beta_{2} \text { age }+\beta_{3} \text { benftLs }+\beta_{4} e d u+\beta_{5} g n d r+\beta_{6} \text { landarea }+u_{i}
$$

Where, $\mathrm{L}_{\mathrm{i}}$ is probability of being poor, $\beta_{0}=$ Intercept, $\mathrm{X}_{1}=$ Total number of family members, $\mathrm{X}_{2}=$ Age of household head, $\mathrm{X}_{3}=$ Livestock benefit of household, $\mathrm{X}_{4}=$ Education of household, $\mathrm{X}_{5}=$ Gender of household head, $\mathrm{X}_{6}=$ Landholding of Household, $\mu_{\mathrm{i}}=$ Error term. 


\subsection{Maximum Likelihood Ratio (MLE)}

In logit model coefficient are estimated through MLE because it maximize log likelihood rather to minimize the residual $[24,13]$.

\subsection{Odds Ratio}

Odds ratio is estimated to express the probability of occurrence of an event. One unit change in explanatory variable changes the odds which is estimated by exponentiation the resulted parameter $\mathrm{e}^{\beta}$ termed as odd ratio. If its value is greater than 1 it means that the independent variable increases the odds of occurrence of the outcome and vice versa $[4,5]$.

\subsection{Marginal Effects}

As in OLS, marginal effects are used as a basic measure for the description of result in logistic regression model. Both measures are similar with little contrast that is OLS measure the instant change in dependent variable due to unit change in independent variable while marginal effects calculate the distinct change in estimated probability due to a unit change in independent variable [53].

\subsection{Multicollinearity Test}

Before estimation of the logit model it is essential to check the existence of the multicollinearity amongst the continuous variables because the presence of the multicollinearity will affect the importance of parameter or estimates. If the multicollinearity goes out and shows to be significant than the instantaneous existence of the two variables can be weaken as well as strengthen the distinct effects of these variables so, by omitting the significant collaboration terms inaccurately will lead towards a specification biasness. In simple words, the coefficients of the interaction among the variables designate whether one of the double associated and related variables ought to be abolished from the model analysis [11]. Variance Inflation Factor (VIF) is a technique that is helpful to perceive the problems of multicollinearity for independent variables [14] .

$$
\operatorname{VIF}\left(\mathrm{X}_{\mathrm{j}}\right)=\frac{1}{1-R^{2}}
$$

Here $R^{2}$ is the coefficient of determination of the variable $j$ which is regressed on the remaining quantifiable independent variables. An increase in the value of $\mathrm{R}^{2}$ shows that the degree of multicollinearity tends to increase, which lead to rise in the variances as well as the standard errors of the OLS estimations. A value of VIF is greater than the 10 such as it will occur if $\mathrm{R}^{2}$ is surpasses 0.90 , so it is used by sign designed for presence of unadorned multicollinearity [15].

\section{Results and Discussion}

\subsection{Poverty Estimation}

The poverty estimates of the three districts namely Gilgit, Hunza and Nagar compared with estimated poverty line are highlighted in Table 1. The result of Hunza district shows that 74 percent households are absolute poor, depth of poverty is 37 percent and severity is 22 percent. For district Nagar incidence of poverty is 38 percent, depth is 19 percent while 10 
percent people are severely poor. In the same way results of Gilgit district show 32, 19 and 12 percent incidence, depth and severity of poverty respectively. Table also shows that on average 44 percent people are living below poverty line in study area for the year 2016-17. Overall depth of poverty is 23 percent which means that and 13 percent SPGR for overall sampled areas of Gilgit Baltistan. It means 44 percent people on average are living below poverty line in research area while depth of poverty is 23 percent which means if resources are mobilized equal to 23 percent of the poverty line 3401.82 poor individuals can be transferred to the non-poor as it is the amount needed to bring each individual up to the poverty line and then at least in principle, poverty could be eliminated. For overall district severity of poverty 13 percent which indicates severe inequality among households of the rural area.

The comparison of poverty incidences across the districts of rural areas shows the proportion of rural households living in poverty being markedly highest in Hunza and Nagar respectively. According to the household survey results, the depth of poverty is higher in Hunza, followed by Nagar and Gilgit districts of selected rural areas, implying that more resource is required to bring the poor households out of poverty in Hunza than Nagar and Gilgit.

Table:1 Poverty Profile of Gilgit

\begin{tabular}{|c|l|l|l|}
\hline Districts & HCR & PGR & SPGR \\
\hline Hunza & 0.74 & 0.37 & 0.22 \\
\hline Nagar & 0.38 & 0.19 & 0.10 \\
\hline Gilgit & 0.32 & 0.19 & 0.12 \\
\hline Total & 0.44 & 0.23 & 0.13 \\
\hline
\end{tabular}

\subsection{Diagnostics of the Econometric Model}

Before applying logit model multicollinearity of the independent variables was tested.

\subsubsection{Multicollinearity Test}

Annex-I shows the results of VIF and Tolerance and reflects that the designated data set has no problem of multicollinearity because of the value of each variable lies below the given criteria of the value 10 which recommended that the multicollinearity is not an issue. According to [12] multicollinearity is an issue if the value of any estimates is greater than or equal to 10 .

\subsubsection{Coefficient Estimation of Logistic Regression}

The coefficient estimates of logistic regression model are shown in Table 2, which shows that benefit from livestock are statistically significant and reduce the chance of vulnerability toward poverty. This is understandable that livestock benefit means as a backbone for rural people livelihood. Livestock benefits are source of food, way of income, social security etc. More prominently, shock- absorbing ability of rural depends on livestock earning. Thus, those who own more livestock might be non-poor than otherwise. This is similar with the findings of [37] and[25] that the more the livestock the more the benefit and lower is the poverty level so are more likely to become better off. 
Table 2: Estimated Measure of Logit Model

\begin{tabular}{|c|c|c|c|c|c|c|}
\hline Covariate & Coefficient & $\begin{array}{l}\text { Odd } \\
\text { Ratio }\end{array}$ & $\begin{array}{l}\text { Marginal } \\
\text { Effect }\end{array}$ & $\mathbf{X}$ & Z-Value & P-Value \\
\hline Constant & 7.41 & & & & 3.95 & 0.00 \\
\hline HH size & 0.44 & 1.55 & 0.11 & 0.19 & 0.75 & 0.45 \\
\hline Age & -0.05 & 0.95 & -0.01 & 44.06 & -2.12 & 0.03 \\
\hline $\begin{array}{l}\text { Benefit } \\
\text { Livestock }\end{array}$ & -1.63 & 0.19 & -0.38 & 0.81 & -2.46 & 0.01 \\
\hline $\begin{array}{l}\text { Education } \\
\mathrm{HH}\end{array}$ & -1.15 & 0.31 & -0.24 & 0.02 & -0.72 & 0.47 \\
\hline Gender & -1.42 & 0.24 & -0.34 & 0.67 & -2.28 & 0.02 \\
\hline $\begin{array}{l}\text { HH Own } \\
\text { Land }\end{array}$ & -.32 & 0.72 & -0.08 & 9.39 & -3.29 & 0.00 \\
\hline \multicolumn{3}{|c|}{ Pseudo $\mathrm{R}^{2}$} & \multicolumn{4}{|l|}{0.22} \\
\hline \multicolumn{3}{|c|}{ Likelihood Ratio } & \multicolumn{4}{|c|}{$30.6(0.0000)$} \\
\hline \multicolumn{3}{|c|}{ Pearson goodness of fit test } & \multicolumn{4}{|c|}{$94.8(0.19)$} \\
\hline \multicolumn{3}{|c|}{ Hosmer-Lemeshow goodness of fit test } & \multicolumn{4}{|c|}{$5.35 \%$} \\
\hline \multicolumn{3}{|c|}{ Sensitivity Value } & \multicolumn{4}{|l|}{$73.4 \%$} \\
\hline \multicolumn{3}{|c|}{ Specificity Value } & \multicolumn{4}{|l|}{$74.5 \%$} \\
\hline \multicolumn{3}{|c|}{ Correctly Specified } & \multicolumn{4}{|l|}{$74.0 \%$} \\
\hline \multicolumn{3}{|c|}{ Area Under ROC curve } & \multicolumn{4}{|l|}{0.80} \\
\hline \multicolumn{3}{|c|}{ Iteration } & \multicolumn{4}{|l|}{6} \\
\hline
\end{tabular}

Source: Researcher's own estimation

Gender of household head is negative and significant towards poverty, this infers that male headed households are less likely to be poor than female headed households for the sake that male headed households are in better position of escaping out of poverty than the female headed ones. The possible explanation is that regarding farming experience males were in a better position than the female farmers. This is alike with the findings [36] that the female headed households are more likely to be poor. The findings of this study reflects that rise in household size has a positive relation with poverty this is because of the burden that large family size increase poverty level but family size has insignificant effect on poverty which shows that if there were higher numbers of household members in the family unit the higher the likelihood of such a family unit to own livestock. More household members reduced the costs for employing people to look after livestock since they provide family labor so increase in family size has no effect on poverty. Age of household head is negatively and significantly related to poverty which refers that older individuals have relatively more affluent experience in farming activities so are less poor. This is similar with the findings [41] that the age of the household head is negatively related with poverty. The land holding of the household is statistically significant and negative towards poverty and is similar to the result of [17] which means that more land provides more opportunity of farming practices for the rural people thus reduce the chances of poverty.

\subsubsection{Odd Ratio Estimates of Logit Model}

Odd ratio is a different way of explaining the results, as in our research value for poor is 1 and for non-poor is so less than 1 value is desirable. According to results given in Table 2 the value of odd in favor of being poor to non-poor is 0.94 for head age which means that head age on average decrease the odd of being poor by 6percent. However, the odd of education of household is 0.31 with insignificant statistics ( $P$ value greater than 0.005 ) which indicate that in 2016-17 education of household has no effect on poverty. The value of odd in favor of being poor to non-poor is 0.72 for owned land which narrates that land 
holding on average decrease the odd of being poor by 28 percent. Odd ratio of gender is 0.24 which indicates that the odd of being poor decrease on average by 76 percentif male household head involve in income generating activities of house. Estimated odd of family size is 1.55 with insignificant value which shows that increase in number of family has no effect on poverty. The value of odd in favor of being poor to non-poor is 0.19 for the benefit from livestock asset which clearly explains that livestock benefit on average decrease the odd of being poor by $81 \%$ for rural households. It shows that livestock are very important source for poverty reduction in the rural areas of Gilgit Baltistan.

\subsubsection{Marginal Effects Estimates of Logistic Regression}

The values of marginal effects shown in table 2 tell that one unit increase in the independent variable above a certain threshold level $\mathrm{X}$ will change the poverty by the value of estimates. The results suggest that if the age of household head increase by one year above approximately 44 years the probability of being poor to non-poor decrease by 1percent. In case of land holding of household, if land size increases by one unit above 9.39 kanals the probability of being poor decreases by 8 percent. The estimated results of education of the household and household size are insignificant which show that these variables have no effect on poverty of the households in 2016-17. Benefits from livestock and gender are dichotomous variables so there is no worth of using this threshold interpretation.

\subsubsection{Goodness of Fit and Accuracy Estimates of Logistic Regression}

In logistic regression model goodness of fit has been tested by using Pseudo $\mathrm{R}^{2}$ which shows that the correlates of poverty investigated in this study have explained 22 percent variation in the model and it is quite matches with any cross sectional analysis. $\mathrm{P}$ values for Pearson goodness of fit (0.19) and likelihood ratio (0.000) are less than 1 which indicates that at least one of the coefficient is non-zero and whole model is good fitted and results are highly significant.

\subsubsection{Tests for Predictive Accuracy}

Predictive Accuracy of the given model was tested by using Specificity and Sensitivity values and Receiving Operating Curve (ROC). Specificity measures the percentage of true negative correctly specified while Sensitivity measure that of positive. ROC is plotted with sensitivity and specificity on the vertical axis for each cut off point shown in Annex-II and III. Value of Specificity for logistic distribution is 74.5 percent and sensitivity is 73.4 percent. High value of both estimates is preferable and gives correct prediction about events and non-events. Model is correctly specified by 74 percent. These two measures collectively give the value of ROC. In present study area under ROC is 0.80 showing that logistic model is excellent and is indicating good predictive accuracy as shown in table 2 .

\section{Conclusion}

Gilgit Baltistan is endowed with many natural base resources and rural population is directly and indirectly involved in livestock production. In this study the three common poverty estimates have been found to be 44 percent, 23 percent and 13 percent for head count, poverty gap and poverty severity, respectively for selected rural areas of Gilgit Baltistan. District wise poverty estimation reflects highest poverty in Hunza. The results of 
the econometric model indicated the influence of different variables on household poverty. A total of six independent variables were included in the model out of which four variables had showed the significant and negative effect towards poverty. Benefit from the livestock, age of the household and gender and holding land had a significant and negative association with poverty status. On the contrary, household size was found to be positive and education had negative but insignificant influence on poverty respectively. So the research concludes that livestock is essential for rural economy of study area as it plays a significant role in poverty eradication and for sustaining livelihood of deprived people.

\subsection{Recommendations}

The policy implications mentioned below are suggested as major recommendations on the basis of key findings of this research endeavor.

1. The study area was deprived of major veterinary services and proper market facilities. Therefore, establishment of veterinary service center and proper market in the study area can enhance the income level of the household thus descend poverty. Area specific interventions would be more beneficial.

2. Provision of microcredit to the female farmers for livestock rearing can stimulate the female contribution towards livestock farming and subsequently address gender inequality issue.

3. Livestock management based trainings in the study area can elevate the capacity building of livestock farmers.

In order to decrease any expected negative effects of livestock production on environment some improved environment friendly technologies are required to be introduced to reap the maximum socioeconomic benefits for sustainable economic growth.

\section{References}

1. A. Aleme, and Z. Lemma, Contribution of Livestock Sector in Ethiopian Economy: A Review, Advances in Life Science and Technology, 23,1-13 (2015)

2. A. Ali, \& M. Khan, Livestock ownership in ensuring rural household food security in Pakistan, J Anim Plant Sci, 23(1), 313-8 (2013)

3. A. B. Johannesen, \& A. Skonhoft, Livestock as insurance and social status: Evidence from reindeer herding in Norway, Environmental and resource economics, 48(4), 679$694(2011)$

4. A. Field, Discovering statistics using SPSS. 2nd eds (Sage Publications, London, 124$189,2005)$

5. A. I. Abdelrahman, Applying logistic regression model to the second primary cancer datahttp://interstat.sta2010/articles/1001006.pdf.Searched on 30-12-2010 (2010)

6. A. M. McSweeney,\& C. Raish, Social, cultural, and economic aspects of livestock ranching on the Santa Fe and Carson National Forests, Rocky Mountian Research Station, Forest Service, US Department of Agriculture (2012)

7. A. Rehman, L.Jingdong, A. A. Chandio, \& I. Hussain, Livestock production and population census in Pakistan: Determining their relationship with agricultural GDP using econometric analysis, Information Processing in Agriculture, 4(2), 168-177 (2017) 
8. A. Siddiqui, Economic Developments in the age of Globalization Sharpe Reference, a, b, c, India and South Asia, 419 (2006)

9. AKRSP, An assessment of socio economic trend and impact in Northern Areas (19911997): Findings from AKRSP's farm household income and expenditure survey Gilgit, Aga Khan Rural Support Program (2000)

10. B. J. Gentner, \& J. A. Tanaka, Classifying federal public land grazing permittees , Journal of Range Management, 2-11 (2002)

11. C. R. Kothari, Research Methodology: Methods and Techniques. Second Edition (Washwa Prakashan Pub, New Delhi, India, 1990)

12. D. Asteriou,\&S. G Hall, Applied econometrics (Palgrave Macmillan, New York, 2011)

13. D. N. Gujarat, (2005).Basic Econometrics. Fourth Edition (Mc. Grawhill Inc, New York, 2005)

14. D. N. Gujarati, Basic Econometrics, Third edition (McGraw-Hill Inc, New York, 1995)

15. D. N. Gujarati, Basic Econometrics, 4th edition (The McGraw-Hill Companies, New York, 2004)

16. DAAF.(2012). The framework for the Zero Hunger Programme. Actuating The irrigated food security strategy for South Africa, Department of Agriculture, Forestory and Fisheries (DAAF), South Africa.

17. F. F. Shugri, Dimensions and Determinants of Poverty in Agro-Pastoral Households of Kabribayah District, Fafan Zone, Somali Regional State, Ethiopia (Doctoral dissertation, Haramaya University, Haramaya) (2016)

18. F. J. C. Swanepoel, A. Stroebel, \& E.Nesamvuni, Key Functions of livestock in Smallholder Farming Systems: A South African Case Study, Animal Production Australia, 24, 237-240 (2002)

19. F. Swanepoel, A.Stroebel, \& S. Moyo, The role of livestock in developing communities: Enhancing multifunctionality. University of the Free State and CTA (2010)

20. FAO.(2006). Livestock's Long Shadow, released by the Food and Agriculture Organization of the United Nations.

21. FAO.(2009). The State of Food and Agriculture Livestock in Balance, http://www.fao.org/docrep/012/i0680e/i0680e.pdf, accessed 21.02.14.

22. FAOSTAT.(2013). Statistical database of the Food and Agriculture Organization of the United Nations.http://faostat3.fao.org/.

23. G. Mudzielwana, Determinants of cattle ownership and herd size in Vhembe District of Limpopo Province, South Africa (Doctoral dissertation, University of Limpopo) (2015).

24. G. S. Maddala, Introduction to Econometrics.Third edition.(Wiley India Ltd. p. 316332, India, 2007) 
25. G. Semer, Dimension and Determinants of rural household Poverty: The Case of Eastern Zone in Tigray National Regional State, An MSc Thesis Presented to the School of Graduate Studies of Haramaya University, Haramaya (2008).

26. G.S. Maddala, Limited Dependent and Qualitative Variables in Econometrics (Cambridge University Press, 1989).

27. GoP. (2016-17). Over view of the economy.Ministry of Finance. http://www.finance.gov.pk/survey/chapters_17/overview_2016-17.pdf.10-11.

28. J. Clemens, Human and economic issues associated with livestock production. Livestock, Fodder, Pastures and People: An Integrated Study in the Northern Areas of Pakistan, International Centre for Integrated Mountain Development, Kathmandu, Nepal, 35-56 (2005)

29. J. H. Aldrich, \&F. D. Nelson, Linear probability, logit, and probit models (Vol. 45) (Sage, 1984).

30. J. Klugman, A Sourcebook for Poverty Reduction Strategies: Volume 2: Macroeconomic and Sectoral Approaches (World Bank, Washington DC, 2002)

31. J. M. Kandulu, B. A. Bryan, D. King, \& J.D. Connor, Mitigating economic risk from climate variability in rain-fed agriculture through enterprise mix diversification, Ecological economics, 79, 105-112 (2012)

32. L. De Haan, \& A. Zoomers, Development geography at the crossroads of livelihood and globalization, Tijdschriftvooreconomischeensocialegeografie, 94(3), 350-362 (2003)

33. L.H. Dossa, B. Rischkowsky, R.Birner, \& C. Wollny, Socio-economic determinants of keeping goats and sheep by rural people in southern Benin, Agriculture and human values, 25(4), 581 (2008)

34. L.W Bell, \& A. D. Moore, Integrated crop-livestock systems in Australian agriculture: Trends, drivers and implications, Agricultural Systems 111, 1-12 (2012)

35. M. A. Iqubal, Role of livestock husbandry on rural transformation in north india: a case study, Revijazageografijo 5(2), 83-94 (2010).

36. M. Abdikadir, Dimensions and Determinants of Poverty in Agro-Pastoral Households of Jigjiga District, Somali National Regional State, Ethiopia. An MSc Thesis Presented to the School of Graduate Studies of Haramaya University, Haramaya, (2013)

37. M. Hilina, Dimensions and determinants of poverty in pastoral areas of Eastern Ethiopia: The case of Shinile zone in Somali national regional state. An MSc Thesis, Haramaya University, Ethiopia, 125 (2005)

38. M. I. Meltzer, Livestock in Africa: The economics of ownership and production, and the potential for improvement, Agriculture and Human Values, 12(2), 4-18 (1995).

39. M. Jodlowski, A. Winter-Nelson, K.Baylis, \&P. D. Goldsmith, Milk in the data: food security impacts from a livestock field experiment in Zambia, World Development, 77, 99-114 (2016) 
40. M. M. Islam, S. Anjum, R.J. Modi, \&K. N. Wadhwani, Scenario of livestock and poultry in india and their contribution to national economy. International Journal of Science, Environment and Technology, 5(3), 956-65 (2016).

41. O. A. Omotesho, A Gender Analysis of Poverty among Rural Farming Households in North Central Nigeria, European Journal of Social Science, 28(3), 366-376 (2012)

42. P. R. Lawrence, W. R. Meghan, K.A. Debra,\& A. D Teresa, Importance of Animals in Agricultural Sustainability and Food Security, 1-3 (2015).

43. Pirwahab, Livestock and Rural Livelihood in Pindsultani, Attock. The Exployer, Journal of Social Sciences, 1(2), 51-53 (2015).

44. R. S. Pindyck, \& D. L. Rubinfeld, Econometric Models and Economic Forecasts, (McGraw-Hill Book Co., New York, 1981).

45. S. L. Jackson, Research Methods and Statistics: A Critical Thinking Approach volume 3. (Belmont, CA, Wadsworth, 2009).

46. S. Reist, F. Hintermann, \& R. Sommer, The livestock revolution: An opportunity for poor farmers. Funded by Swiss Agency for Development and Cooperation.Switzerland, 1-1 (2007)

47. T. Amemiya, Qualitative response models: A survey. Journal of economic literature, 19(4), 1483-1536 (1981).

48. T. Liao, Interpreting Probability Models: Logit, Probit, and other Generalized Linear Models. Sage University Paper Series on Qualitative Application in the Social sciences. Thousand Oaks. CA: (Sage, 1994)

49. T. Serik, K. Musabekov, A. Yesbolova, S.Ibraimova, A. Mergenbayeva, Z. Sabdenova, \& M. Seidahmetov, Issues in the Development of the Livestock Sector in Kazakhstan. Procedia-Social and Behavioral Sciences, 143, 610-614 (2014)

50. T. Yamane, Statistics, An Introductory Analysis, volume no.2, (Harper and Row, New York, 1967)

51. UNDP, Livestock-based Micro-enterprise and Its Effectiveness on Poverty Reduction: A Study in Hansposa VDC of Sunsari District, 3: 8 (2013)

52. V. Alary,C. Corniaux,,\& D. Gautier, Livestock's contribution to poverty alleviation: How to measure it?. World Development, 39(9), 1638-1648 (2011)

53. W. H. Green, Econometrics Analysis.Fifth Edition. (Dorling Kindersley, India, 2003)

54. WB, World Bank prepared a book entitled, Livestock Development: Implication for Rural Poverty, the Environment and Global Food Security (2001) 


\section{Annex-I}

\section{Variance Inflation Factor and Torelance}

- vif

\begin{tabular}{|c|c|c|}
\hline Variable & $V I F$ & $1 / V I F$ \\
\hline age & 1.49 & 0.672010 \\
\hline gender & 1.39 & 0.718571 \\
\hline livestockb t & 1.10 & 0.911794 \\
\hline education & 1.05 & 0.948721 \\
\hline hhlandarea & 1.04 & 0.963037 \\
\hline$h h_{\text {_tsize }}$ & 1.03 & 0.969523 \\
\hline Mean VIF & 1.18 & \\
\hline
\end{tabular}

\section{Annex-II}

\section{Sensitivity-Specificity Curve}

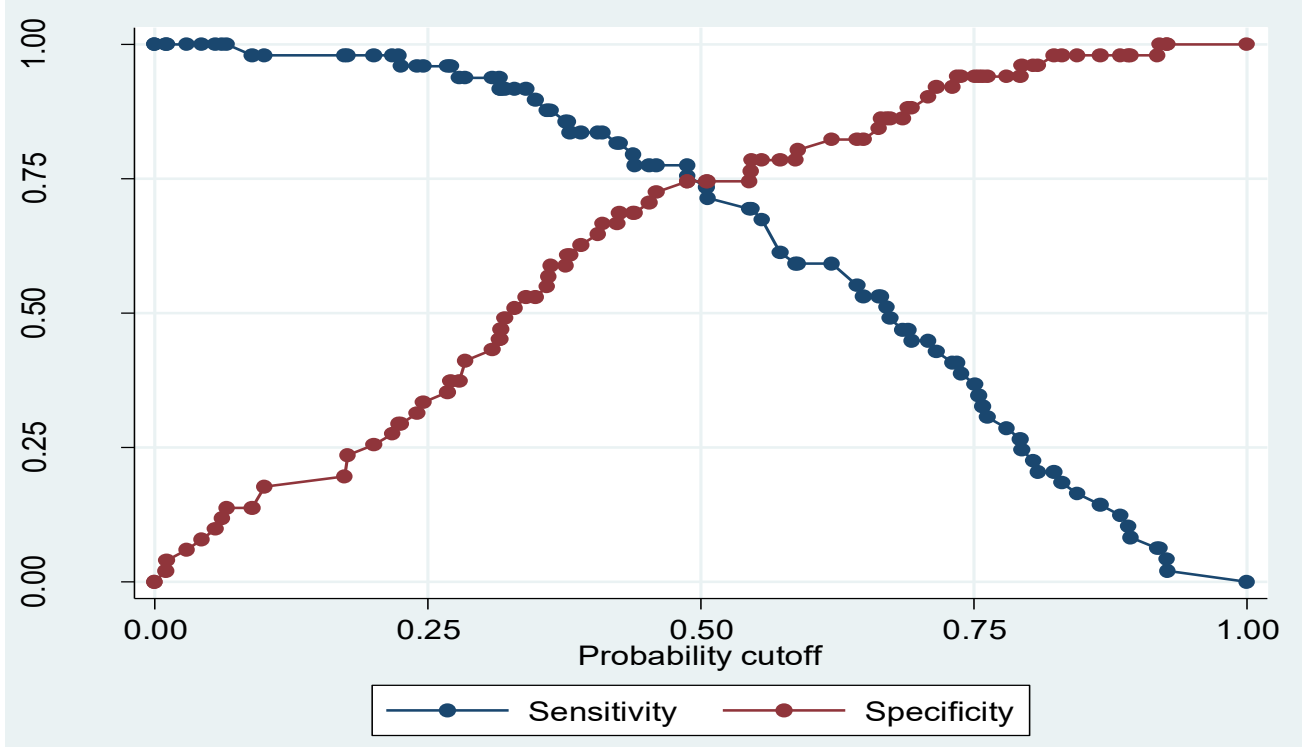




\section{Annex-III}

\section{Receiving Operating Curve (ROC)}

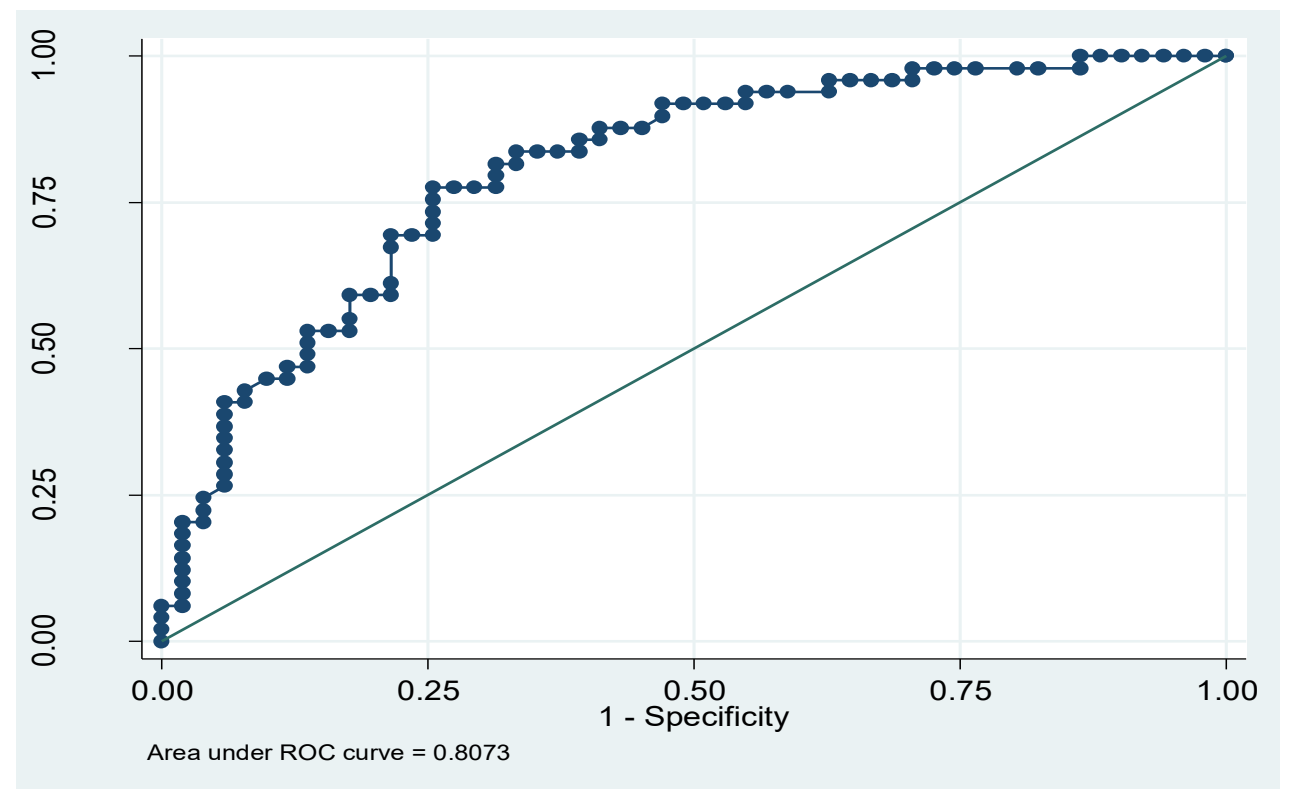

